\title{
Insect (Hexapoda) diversity in the oceanic archipelago of Fernando de Noronha, Brazil: Pipunculidae (Diptera)
}

\author{
José A. Rafael ${ }^{1(\mathbb{D}}$, Dayse W. A. Marques ${ }^{1(\mathbb{D})}$, Alberto M. Silva-Neto ${ }^{1 \pm=(\mathbb{D}}$, Francisco Limeira-de- \\ Oliveira2 ${ }^{2}$
}

${ }^{1}$ Instituto Nacional de Pesquisas da Amazônia, Coordenação de Biodiversidade, Manaus, AM, Brazil. ${ }^{2}$ Universidade Estadual do Maranhão, Centro de Estudos Superiores de Caxias, Caxias, MA, Brazil.

䤵CCorresponding author: bio.alberto@gmail.com

Edited by: Eduardo Amat

Received: December 16, 2020. Accepted: February 24, 2021. Published: February 26, 2021.

Abstract. Eudorylas lepus (Rafael, 1990) is recorded for the first time in Fernando de Noronha. It is recorded in low number of specimens and it is shortly characterized.

Keywords: Fernando de Noronha archipelago, big headed flies, endoparasitoid, neotropics, oceanic islands fauna, Eudorylas.

Pipunculids, also known as big-headed flies, are small flies measuring 2.0-11.5 mm long (Rafael \& Skevington 2010). Due to their biology, they have great potential as bio controllers of hemipteran pests, naturally attacking leafhoppers and planthoppers (Virla \& Rafael 1996). They are endoparasitoids of several Hemiptera (Auchenorrhyncha) families, including Cicadellidae, Cercopidae, Delphacidae, Membracidae, Issidae, Cixiidae, and Flatidae (Rafael \& Skevington 2010), the first four families present in Fernando de Noronha (Rafael et al. 2020). Despite the economic importance of the group, few data on host relationships exist in Neotropical Region (Virla et al. 2009).

The fauna of Pipunculidae has been recorded in some oceanic islands, generally in low number of species. In the Pacific Ocean, Galápagos Archipelago with one named and one undetermined species (Sinclair 2009). In the Greater and Lesser Antilles there are several countries with Pipunculidae records, summarized by Rodriguez \& Rafael (2012) or other references as informed: Bahamas (7 species); Bermudas (1); Cuba (6); Dominica (8) (Scarbrough \& Knutson 1989); Hispaniola (Dominican Republic and Haiti) (20) (Perez-Gelabert 2020); Jamaica (10); Puerto Rico (3); St. Lucia (1); St. Vincent and Grenadines (3).

This paper is part of a series by the authors that is treating the fauna of insects (Hexapoda) of Fernando de Noronha (FN). The first paper dealt with the updated taxonomic checklist citing 453 species or morphospecies of insects (Rafael et al. 2020). Here we advance in the results for Pipunculidae (Diptera), previously recorded based on undetermined female specimens at genus level, as Eudorylas sp. Its presence poses an important biological function as controllers of pests in the island.

The Brazilian oceanic archipelago of Fernando de Noronha is located at the equatorial South Atlantic region (latitude $3^{\circ} 45^{\prime} \mathrm{S}$ to $3^{\circ} 57^{\prime} \mathrm{S}$; longitude $32^{\circ} 19^{\prime} \mathrm{W}$ to $32^{\circ} 4^{\prime} \mathrm{W}$ ) (Fig. 1) and it has a tropical oceanic climate (Awi - Köppen classification). The temperature ranges from $23.5^{\circ} \mathrm{C}$ to $31.5^{\circ} \mathrm{C}$, with an annual mean of $28^{\circ} \mathrm{C}$ (IBAMA 2006) and annual precipitation of $1,400 \mathrm{~mm}$, but with large interannual variability. Additional information in Freitas et al. (2013) and Rafael et al. (2020). The collecting license number for this project is 62.821 , issued by Instituto Chico Mendes de Conservação da Biodiversidade (ICMBio). Pipunculid specimens were collected with Malaise interception traps and will be deposited at INPA, Instituto Nacional de Pesquisas da Amazônia, Manaus, Amazonas and CZMA, Coleção Zoológica do
Maranhão, Caxias, Maranhão.

Three sites on the main island Fernando de Noronha (Fig. 1B) were selected for interception traps based on the following criteria: accessibility, diversity of vegetation, low degree of exposure to human activities, and geographical position inside the National Park area. The three sites with continuous collection using interception traps (Fig. 1B) are: 1) Sancho-Dolphins Bay trail, near the information and control desk, using two interception traps, model Townes (Townes 1972), placed around 100 meters from each other; 2) next to the lookout at Dolphins Bay, using one interception trap, model Gressitt \& Gressitt (1962) and; 3) on the Capim-Açu trail, one interception trap, model Gressitt and Gressitt. The collecting activities were interrupted on March 15, 2020, as a result of the covid-19 pandemic. Specimens were labelled, preserved in small containers with commercial ethanol $\left(94^{\circ}\right)$, dried and pinned.



Figure 1. Geographical records of Eudorylas lepus (Rafael, 1990). 1A. South America; 1B. Fernando de Noronha.

A total of 15 adult specimens of Eudorylas lepus (Rafael, 1990) were collected, being two males and two female specimens at Sancho, along the trail Sancho-Dolphins Bay, one male and one female specimens at Capim-Açu trail and seven males and two female specimens at Dolphins Bay.

Eudorylas Aczél, 1940 is a cosmopolitan and highly heterogeneous genus. Specimens belonging to Eudorylas are characterized by the postpedicel with apex acute to subfiliform; dorsocentral setae diminute; propleuron without setae, pterostigma present; vein $M_{2}$ absent; abdomen with inconspicuous setae; tergite 6 and sternite 7 
visible from dorsal view; syntergosternite 8 usually with membranous area; surstyli asymmetrical or subsymmetrical, usually with bases larger than apices; apex of phallic guide generally with distinct setose subapical lobe and small protuberances; ejaculatory apodeme fan shaped, arranged transversely to the sperm pump, the later with two proximal lobes and three somewhat elongated ejaculatory ducts (Rafael 1987).

\section{Eudorylas lepus (Rafael, 1990) (Figs. 2-6)}

The genus was recorded only recently to the Fernando de Noronha island based on female specimens (Rafael et al. 2020) and now it is being identified at specific level based on male specimens, thus this is the first record of one species in an oceanic island in the South Atlantic Ocean.

This species is characterized by body length around $3.9 \mathrm{~mm}$; wing length around $4.6 \mathrm{~mm}$ (Fig. 2); antenna with pedicel dark brown to black, postpedicel yellow; legs (Fig. 2) mainly yellow with fore and mid femora dark brown to black dorsally, hind femur almost entirely dark brown to black (only dark brown dorsally in Fernando de Noronha specimens); tergites opaque, mostly brown pruinose; syntergosternite 8 with membranous area (Fig. 3); both surstyli with bases wider than apices (Fig. 4); apex of phallic guide backward curved and with subapical protuberances directed laterally (Figs. 5-6). The variation in color of hind femur of the Fernando de Noronha specimens apparently is a local variation, however genital characteristics easily identify these specimens as E. lepus.

Geographical records. Brazil: Rio de Janeiro, São Paulo, Paraná, Santa Catarina (Marques \& Rafael 2021) and Pernambuco, Fernando de Noronha (new record) (Figs. 1A, 1B).

Material examined. BRASIL, PE[rnambuco], Fernando de Noronha, Sancho, $3^{\circ} 51^{\prime} 17^{\prime \prime} S-32^{\circ} 26^{\prime} 26^{\prime \prime} \mathrm{W}$, Malaise, J.A. Rafael, F. Limeira-deOliveira, L. C. Castro in the following places and data along nine months from June/2019 to February/2020: Dolphins bay, 23.vi-7.vii.2019 (1ㅇ) ; 9-23.vii.2019 (1ठ̂); 23.vii-5.viii.2019 (1ㅇ); 20.viii-8.ix.2019 (5ふ); 9-24.x.2019 (1ð); Sancho-Dolphins Bay trail, 23.vii-5.viii.2019 (1ठ̂); 7-21.viii.2019 (1ㅇ)); 20.viii-8.ix.2019 (1ર̂); 26.xi-8.xii.2019 (19); Capim-
Açu trail, 23.vii-5.viii.2019 (1つ̋); 9-24.x.2019 (1ㅇ).

Remarks. Specimens of Eudorylas were already recorded parasitoidizing specimens of Scaphytopius Ball, 1931 (Hemiptera, Cicadellidae) in Argentina (Virla et al. 2009), a genus already recorded in Fernando de Noronha (Alvarenga 1962; Rafael et al. 2020) and it is a potential host for E. lepus in this archipelago.

Fernando de Noronha is one of the smaller islands around the world but the larger one belonging to Brazil. Its biota certainly is among the most threatened in the world. The insect fauna is still poorly known, and it has been neglected along the time, therefore we strongly encourage future research that contemplate the most diverse aspects of the groups that inhabit the island.

The low abundance and low species richness of pipunculids in the Fernando de Noronha can be tentatively attributed to one predator species, the reptile noronha-skink, or mabuya, Tachylepis atlantica (Schmidt, 1945), with high abundance on the island. Pipunculidae have a slow flight and can hover in the air near leaves or branches looking for hosts; or they also can land on vegetation and in both cases making it an easy prey for this little lizard when the pipunculid is flying or while resting; besides as observed by Kehlmaier (2014) the pipunculid occasionally imbibe nectar and can be easily preyed by the mabuya that also reaches flowers for nectivory (Silva-Neto et al. 2020). Any insect flying around or resting at or near the flower can easily be preyed by the small mabuya.

The origin of the Noronha insect fauna was discussed in Rafael et al. (2020). Concerning the pipunculids we can say that maybe E. lepus arrived in Fernando de Noronha through the human activity while transporting plant species infested with immature or adult leafhoppers and planthoppers, with these parasitoidized by larvae of pipunculids. However, this is only a hypothesis through the inference of the presence of the natural hosts of pipunculids and the fact of their food association with some plants. Among the taxa previously recorded as hosts of pipunculids there are several occurring in Fernando de Noronha as Cicadellidae (8 species), Delphacidae (2) and Membracidae (1) (Rafael et al. 2020).

In nine months using interception traps, that are effective to collect
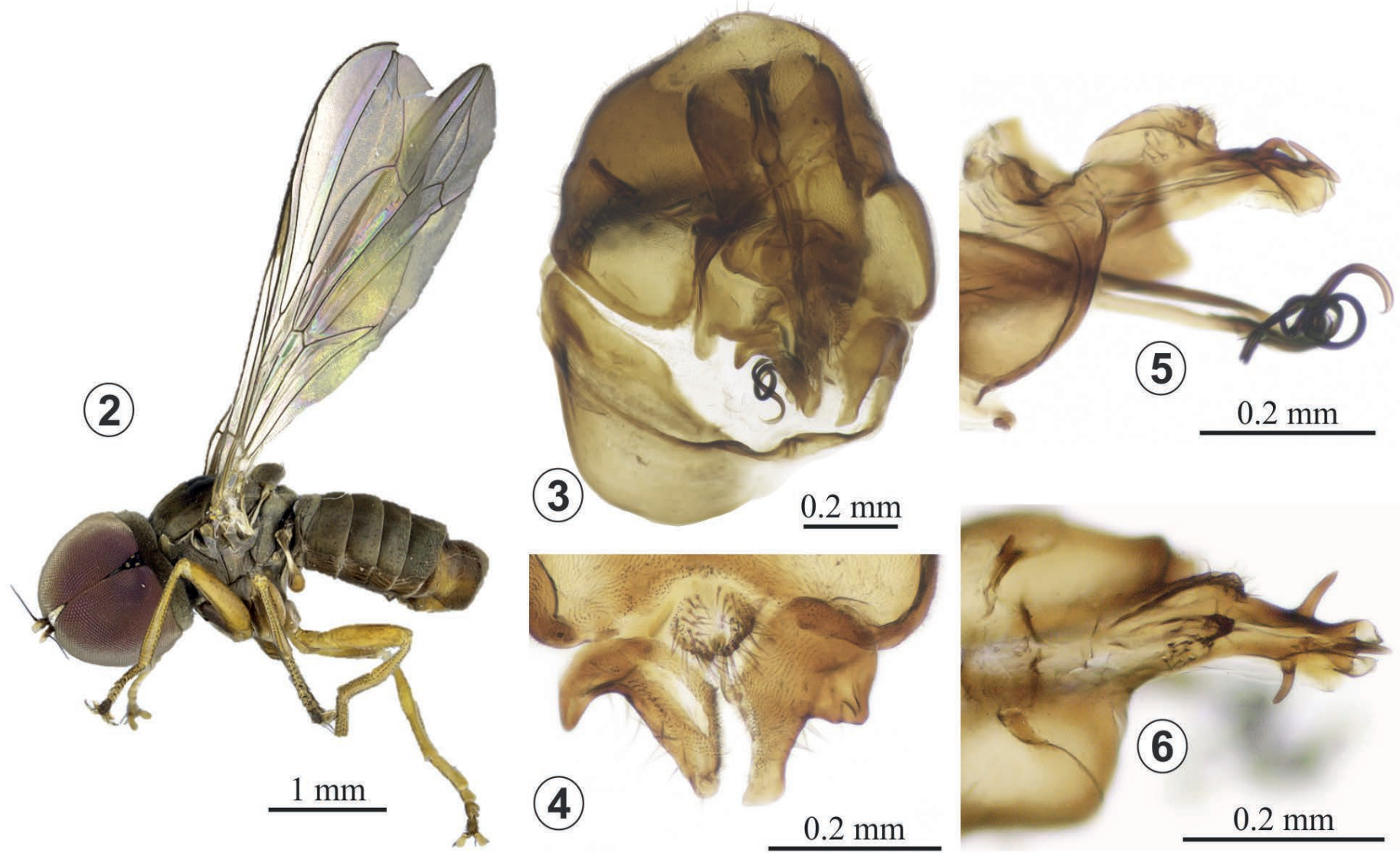

Figures 2-6. Eudorylas lepus (Rafael, 1990). Habitus and terminalia. 2. Habitus, lateral view; 3. Terminalia, dorsal view; 4. Surstyli, dorsal view; 5-6. Phallic guide and ejaculatory ducts, lateral, and dorsal views, respectively. 
pipunculids (pers. obs., JAR), only 15 specimens were collected, and we do not discard the possibility of at least one more species occurring in Fernando de Noronha based on several species of Hemiptera occurring in the archipelago (Rafael et al. 2020). As other groups of insects, Pipunculidae has been neglected in Fernando de Noronha and much work remains, especially studies on their hosts. All pipunculid specimens were collected during the dry season, from June to December and the prediction is that we would find many more specimens of their hosts at this season. No specimen of pipunculid was collected at the beginning of the rainy season (January and February). Most of the specimens were collected in the Dolphins Bay, a place where there were a lot of grasses around the trap and this certainly influenced the collections since their hosts are leafhoppers that attack these plants. Capim-Açu, on the contrary, did not have grasses in the vicinity of the trap and the amount of pipunculid flies collected was the lowest.

\section{Acknowledgements}

We thank the Instituto Nacional de Pesquisas da Amazônia (INPA), for research support. To the Fundação de Amparo à Pesquisa do Estado do Amazonas (FAPEAM) and Conselho Nacional de Pesquisas (CNPq), for financial support Edital 001/2015 - CNPq/MCTI/FAPs/PROTAX, CNPq (process number 440.423/2015-5). To CNPq for a research grant through edital Universal 01/2016 - MCTI/CNPq (process number 405.630/2016-6) and for research fellowships to J.A.R. (process number 300019/2017-3). To Coordenação de Aperfeiçoamento de Pessoal de Nível Superior (CAPES) for the student scholarships and post-doctoral fellowships. To Instituto Chico Mendes de Conservação da Biodiversidade (ICMBio) for the Collecting License number 62.821. To the staff at the Parque Nacional Marinho Fernando de Noronha, Ricardo Araújo, Viviane Vilella and Carolina Fonseca for administrative help. To the Autarquia Territorial do Distrito Estadual de Fernando de Noronha (ATDEFN), for the administrative facilities. To Layane Carvalho de Castro for field support.

\section{Authors' Contributions}

JAR, DWAM and FLO identified the species. DWAM prepared the figures. JAR, DWAM, AMSN and FLO wrote the manuscript.

\section{References}

Alvarenga, M. (1962) A entomofauna do arquipélago Fernando de Noronha, Brasil. Arquivos do Museu Nacional, 52: 21-26.

Freitas, G. C. C.; Brescovit, A. D.; Vasconcelos, S. D. (2013) Spider diversity on the oceanic island of Fernando de Noronha, Brazil, and implications for species conservation. Journal of Insect Science, 13 (148): 1-16. doi: 10.1673/031.013.14801

Gressitt, J. L.; Gressitt, M. K. (1962) An improved Malaise trap. Pacific Insects, 4(1): 87-90.

IBAMA (2006) Parque Nacional Marinho de Fernando de Noronha. http://www.ibama.gov.br. Access on: 10.vii.2020.

Kehlmaier, C. (2014) Big-headed flies do occasionally imbibe nectar (Diptera: Pipunculidae). Studia Dipterologica, 21(1): 91-93.

Marques D. W. A.; Rafael J. A. (2021) Pipunculidae. In: Catálogo Taxonômico da Fauna do Brasil. PNUD. http://fauna.jbrj.gov.br/ fauna/faunadobrasil/1338. Access on: 22.i.2021.

Perez-Gelabert, D. E. (2020) Checklist, bibliography and quantitative data of the arthropods of Hispaniola. Zootaxa, 4749(1): 1-668. doi: 10.11646/zootaxa.4749.1.1

Rafael, J. A. (1987) Two new genera of Pipunculidae (Diptera) from the New World: Metadorylas, gen. n. and Elmohardyia, gen. n., with new synonyms, designation of lectotypes and revalidation of a species. Revista Brasileira de Entomologia, 31(1):35-39.

Rafael, J. A. (1990) As espécies neotropicais de Metadorylas Rafael (Diptera, Pipunculidae). Boletim do Museu Paraense Emílio Goeldi, série Zoologia, 6(2):127-164.

Rafael, J. A.; Skevington J. H. (2010) Pipunculidae (big-headed flies). In: Brown B. V.; Borkent A.; Cumming J. M.; Wood D. M.; Woodley N.
E.; Zumbado M. A. (Eds.), Manual of Central American Diptera, pp. 793-803. Ontario: Canada: NRC Research Press.

Rafael, J. A.; Limeira-de-Oliveira, F.; Hutchings, R. W.; Miranda, G. F. G.; Silva-Neto, A. M.; Somavilla, A.; Camargo, A.; Asenjo, A.; Pinto, A. P.; Bello, A. M., et al. (2020) Insect (Hexapoda) diversity in the oceanic archipelago of Fernando de Noronha, Brazil: updated taxonomic checklist and new records. Revista Brasileira de Entomologia, 64(3): e20200052. doi: 10.1590/1806-9665-RBENT-2020-0052

Rodriguez, H. C.; Rafael, J. A. (2012) Pipunculidae (Diptera) of Latin America and the Caribbean: a catalogue of species with notes on biology and pipunculid-hosts associations. Lambert Academic Publishing Press.

Scarbrough, A. G.; Knutson, L. V. (1989) Asilidae, Bombyliidae, Conopidae, and Pipunculidae (Diptera) of Dominica, West Indies. Florida Entomologist, 72: 519-537.

Silva-Neto, A. M.; Mendes, D. M. M.; Sobral, R.; Oliveira, J. C.; Rafael. J. A. (2020) Trachylepis atlantica (Noronha skink). Nectivory and pollination. Herpetological review, 51(3): 605-606.

Sinclair, B. J. (2009) Dipteran biodiversity of the Galápagos. In: Pape, T.; Bickel, D.; Meier, R. (Eds.), Dipteran Diversity: Status, Challenges and Tools, pp. 97-118. Leiden: Koninklijke Brill NV Press.

Townes, H. (1972) A lightweight Malaise trap. Entomological News, 83: 239-247.

Virla, E. G.; Rafael, J. A. (1996) Datos bionomicos preliminares y descripción de la hembra de Cephalops penepauculus (Hardy) (Diptera: Pipunculidae) un parasitoide de Delphacidae (Homoptera: Auchenorryncha) en Argentina. Revista de Investigación, Tucumán, 10(1/4): 33-36.

Virla, E. G.; Moya-Raygoza, G.; Rafael, J. A. (2009) First Record of Eudorylas schreiteri (Shannon) (Diptera: Pipunculidae) as a parasitoid of the corn leafhopper (Hemiptera: Cicadellidae) in Argentina, with a table of pipunculid-host associations in the Neotropical Region. Neotropical Entomology, 38: 152-154. 